\title{
Midkine Is a Novel Regulator of Amphetamine-Induced Striatal Gliosis and Cognitive Impairment: Evidence for a Stimulus-Dependent Regulation of Neuroinflammation by Midkine
}

\author{
Marta Vicente-Rodríguez, ${ }^{1}$ Rosalía Fernández-Calle, ${ }^{1}$ Esther Gramage, ${ }^{1}$ \\ Carmen Pérez-García, ${ }^{1}$ María P. Ramos, ${ }^{2}$ and Gonzalo Herradón ${ }^{1}$ \\ ${ }^{1}$ Pharmacology Lab, Department of Pharmaceutical and Health Sciences, Facultad de Farmacia, \\ Universidad CEU San Pablo, Madrid, Spain \\ ${ }^{2}$ Biochemistry and Molecular Biology Lab, Department of Chemistry and Biochemistry, Facultad de Farmacia, \\ Universidad CEU San Pablo, Madrid, Spain
}

Correspondence should be addressed to Gonzalo Herradón; herradon@ceu.es

Received 25 August 2016; Accepted 7 November 2016

Academic Editor: Vera L. Petricevich

Copyright (C) 2016 Marta Vicente-Rodríguez et al. This is an open access article distributed under the Creative Commons Attribution License, which permits unrestricted use, distribution, and reproduction in any medium, provided the original work is properly cited.

\begin{abstract}
Midkine (MK) is a cytokine that modulates amphetamine-induced striatal astrogliosis, suggesting a possible role of MK in neuroinflammation induced by amphetamine. To test this hypothesis, we studied astrogliosis and microglial response induced by amphetamine $(10 \mathrm{mg} / \mathrm{kg}$ i.p. four times, every $2 \mathrm{~h})$ in different brain areas of MK-/- mice and wild type (WT) mice. We found that amphetamine-induced microgliosis and astrocytosis are enhanced in the striatum of $\mathrm{MK}-/-$ mice in a region-specific manner. Surprisingly, LPS-induced astrogliosis in the striatum was blocked in MK-/- mice. Since striatal neuroinflammation induced by amphetamine-type stimulants correlates with the cognitive deficits induced by these drugs, we also tested the long-term effects of periadolescent amphetamine treatment $(3 \mathrm{mg} / \mathrm{kg}$ i.p. daily for 10 days) in a memory task in MK-/- and WT mice. Significant deficits in the Y-maze test were only observed in amphetamine-pretreated MK-/- mice. The data demonstrate for the first time that MK is a novel modulator of neuroinflammation depending on the inflammatory stimulus and the brain area considered. The data indicate that MK limits amphetamine-induced striatal neuroinflammation. In addition, our data demonstrate that periadolescent amphetamine treatment in mice results in transient disruption of learning and memory processes in absence of endogenous MK.
\end{abstract}

\section{Introduction}

Drugs of abuse, such as alcohol and amphetamine and its derivatives, induce neuroinflammation [1]. Proliferation of inflammatory cells such as microglia and astrocytes [2] is a signature of neuroinflammation and a hallmark of pathogenesis associated with different events including neurodegeneration [3-5]. Evidence suggests the possibility that neuroinflammatory processes in drug addiction disorders could lead to neurodegeneration in specific brain areas targeted by drugs of abuse. Accordingly, striatal neuroinflammation induced by methamphetamine seems to underlie cognitive deficits, depression, and parkinsonism reported in methamphetamine addicts [6]. In addition, independent studies have demonstrated a highly significant increase in the prevalence of Parkinson's disease (PD) among addicts to amphetaminetype stimulants $[7,8]$. Thus, identification and characterization of new genetic factors involved in drug addiction disorders and inflammation are relevant for validation of new biomarkers and for the development of new drugs that could modulate neuroinflammation processes underlying addiction disorders [9].

Midkine (MK) is a cytokine with important functions in peripheral inflammatory processes in different pathological 
conditions $[10,11]$. MK facilitates the migration of macrophages and neutrophils [12-14] and prevents differentiation of regulatory T-cells by inhibiting the development of tolerogenic dendritic cells $[15,16]$. In the central nervous system (CNS), the role of $\mathrm{MK}$ in inflammation is poorly understood. It has been shown that this cytokine is not involved in the development of astrogliosis or activation of microglia in a spinal cord injury model [17]. However, MK is found highly upregulated in pathologies characterized by inflammation such as cerebral infarction and neurodegenerative diseases $[18,19]$ and in different brain areas after administration of drugs of abuse [20]. This evidence supports the hypothesis that MK could play an important role in neuroinflammation. To test this hypothesis, we have now confirmed that amphetamine-induced striatal astrogliosis is enhanced in MK knockout (MK-/-) mice [21], and we have tested for the first time striatal microglial response induced by amphetamine in $\mathrm{MK}-/-$ and wild type (WT) mice. To test the possibility of a region-specific regulation of astrogliosis by MK, we have also tested the effects of amphetamine in the hippocampus, an area that draws increasing attention as a responsive brain region in psychostimulants actions [22]. We have also investigated if $\mathrm{MK}$ regulates glial response depending on the inflammatory stimulus by comparing the effects of lipopolysaccharide (LPS) injection in MK-/- and WT mice. In addition, since early onset of drug abuse causes a wide range of adverse outcomes in adulthood including cognitive deficits [23], which correlates with the capacity of these drugs to induce striatal neuroinflammation [6], we also tested the long-term effects of periadolescent amphetamine treatment in a memory task in $\mathrm{MK}-/-$ mice.

\section{Materials and Methods}

2.1. Animals. MK-/- mice were kindly provided by Dr. Thomas F. Deuel (The Scripps Research Institute, La Jolla, CA). MK-/- mice were generated as previously described [24]; 8-10-week-old male $\mathrm{MK}-/-$ and WT mice on a C57BL/6J background were used for immunohistochemistry studies; 4-week-old male MK-/- and WT mice were used for periadolescent amphetamine treatment prior to behavioral assessment.

The animals used in this study were maintained in accordance with both the ARRIVE guidelines and the European Union Laboratory Animal Care Rules (Directive 2010/63/EU for animal experiments) and the protocols were approved by the Animal Research Committee of USP-CEU.

\subsection{Histological Studies: Gliosis}

2.2.1. Treatments. MK-/- and WT mice received 4 injections (i.p.) of amphetamine $(10 \mathrm{mg} / \mathrm{kg}$ ) or saline (control, $10 \mathrm{~mL} / \mathrm{kg}$ ), allowing between injections a 2-hour interval. This regimen of administration of amphetamine was previously used to observe differences in the striatal astrocytosis induced by this drug in WT and $\mathrm{MK}-/-$ mice [21]. Four days after the animals received the first administration of amphetamine or saline (control), mice were euthanized for immunohistochemistry studies as described below.
In the study with LPS, MK-/- and WT mice received a single i.p. injection of LPS (Sigma, Madrid, Spain) $(0.5 \mathrm{mg} / \mathrm{kg})$ or saline (control, $10 \mathrm{~mL} / \mathrm{kg}$ ) and were sacrificed $8 \mathrm{~h}$ after the treatment. In order to better dissect possible genotypic differences we used a low dose of LPS that was shown to be useful to test neuroinflammation in mice [25].

2.2.2. Immunohistochemistry Analysis. An equal or greater $n=4$ /group was used in all studies. Mice were transcardially perfused with $4 \%$-formaldehyde, and brains were removed and conserved in $p$-formaldehyde for $24 \mathrm{~h}$ and transferred to a $30 \%$ sucrose solution containing $0.02 \%$ sodium azide for storage at $4^{\circ} \mathrm{C} .30 \mu \mathrm{m}$ striatal and hippocampal free-floating sections were processed as previously described [21, 26, 27]. Immunohistochemistry studies were performed in one slice per $180 \mu \mathrm{m}$ (striatum from bregma $1.54 \mathrm{~mm}$ to $0.10 \mathrm{~mm}$; hippocampus from bregma $-1.06 \mathrm{~mm}$ to $-2.54 \mathrm{~mm}$ ).

In order to study astrogliosis, sections were incubated overnight at $4^{\circ} \mathrm{C}$ with anti-GFAP antibody (Millipore, Madrid, Spain; 1:1000) and then for 30 minutes with the appropriate biotinylated secondary antibody (Vector Laboratories, Burlingame, CA, USA; 1:5000) in PBS at room temperature; the avidin-biotin reaction was performed using Vectastain Elite ABC peroxidase kit (Vector Laboratories) following the protocol suggested by the manufacturer; immunolabeling was visualized by using $3,3^{\prime}$-diaminobenzidine (DAB). Sections were mounted on gelatin-coated slides, airdried overnight, dehydrated through graded ethanol, cleared in xylene, and mounted with DPX medium. To study striatal microgliosis, sections were incubated overnight at $4^{\circ} \mathrm{C}$ with anti-Ibal antibody (Wako, Osaka, Japan; 1:1000), followed by 30 minutes of incubation with Alexa-Fluor-488 secondary antibody (Invitrogen, Waltham, MA USA; 1:500). Photomicrographs were captured with a digital camera coupled to an optical microscope (DM5500B, Leica, Solms, Germany). Analysis was performed using ImageJ (NIH), in the three most central slices of each area. GFAP+ astrocytes were counted in $325 \times 435 \mu \mathrm{m}$ standardized areas in the medial striatum as previously described $[21,26]$ and in the lacunosum moleculare ( $\mathrm{LMol}$ ) located in CA1 area, in the hippocampus. Ibal+ cells were counted in $1100 \mu \mathrm{m} \times 1400 \mu \mathrm{m}$ standardized areas in the striatum.

2.3. Behavioral Studies: Y-Maze. Four independent experiments were performed to reach an appropriate number of subjects per experimental group in Y-maze assays. Treatments began during periadolescence (4-week-old mice). Male MK-/- and WT mice were randomly allocated and injected with either amphetamine ( $3 \mathrm{mg} / \mathrm{kg}$, i.p.) dissolved in saline or saline $(10 \mathrm{~mL} / \mathrm{kg}$, i.p.), once daily for 10 consecutive days. Six days after the last administration of amphetamine (or saline), behavioral testing started following previously published protocols [28] and leaving appropriate "washing" periods of time between different Y-maze assays.

In order to study recognition processes in response to novelty and working memory in mice, we used the Y-maze test as previously described [29]. Memory was measured with a 60 min intertrial interval (ITI) between acquisition and retrieval. During the first trial (acquisition), the animal is 
placed in the centre of the maze and allowed to visit for 5 min two arms ("start" and "other" arms) of a Y-maze with three arms each $34 \mathrm{~cm}$ long, $8 \mathrm{~cm}$ wide, and $14.5 \mathrm{~cm}$ high, the third being blocked with a door. During the second trial (retrieval, $5 \mathrm{~min}$ ), the door is opened, and the animal is free to access all three arms ("start"; "other"; and "novel" arms). During the test, the number of entries into each arm (when a mouse places all four paws into an arm) was recorded. Discrimination of novelty versus familiarity was studied by calculating the preference for the "novel" arm as a discrimination ratio (Novel/[Novel + Other]) for number of arm entries. Scores greater than 0.5 show preference for the "novel" arm indicating the establishment of spatial memory.

Mice (WT: saline, $n=15$; amphetamine, $n=15$, and MK-/-: saline, $n=9$; amphetamine, $n=9)$ were tested in the Y-maze at 6 weeks of age ( 6 days after last amphetamine administration) and 7 and 9 weeks of age. All the experiments were conducted during the light phase.

2.4. Statistical Analysis. Data were analyzed using two-way ANOVA considering genotype and treatment as variants. Relevant differences were analyzed by post hoc comparisons with Bonferroni's post hoc tests. All statistical analyses were performed using GraphPad Prism 6 program (San Diego, CA, USA).

\section{Results}

3.1. Amphetamine-Induced Gliosis in the Striatum Is Enhanced in $M K-/-$ Mice. In order to confirm the previously reported enhanced astrocytosis induced by amphetamine in MK-/mice [21], immunohistochemical analysis of GFAP-positive cells in the striata of $\mathrm{MK}-/-$ and WT mice was performed. Compared to saline-treated animals from both genotypes, amphetamine induced reactive astrocytes characterized by large densely stained bodies with longer and extensive processes (Figure 1(a), black arrows). As expected, amphetamine efficiently increased the number of GFAP+ cells in both genotypes (Figure 1(b)). The number of GFAP+ astrocytes in the striata of amphetamine-treated $\mathrm{MK}-/-$ mice was significantly higher than that in WT mice (Figure 1(b)). The data confirm that $\mathrm{MK}$ regulates amphetamine-induced striatal astrocytic response.

Augmented microglial response is a hallmark of amphetamine derivative-induced neurotoxicity [30] and a signature of neuroinflammation. Immunohistochemistry for Ibal revealed a significant increase in the number of Ibal+ cells in the striata of WT mice 4 days after amphetamine treatment (Figure 2). Compared to saline-treated mice, we found a more pronounced increase in Ibal-ir following amphetamine administration to $\mathrm{MK}-/-$ mice (Figure 2). The data demonstrate for the first time that MK modulates the microglial response induced by amphetamine.

3.2. Genetic Inactivation of Midkine Prevents AmphetamineInduced Astrogliosis in Hippocampus. The data obtained in the striatum of WT and MK-/- mice suggest that MK regulates the glial response induced by amphetamine. The data are particularly robust in the case of the astrocytic response which is highly increased after amphetamine treatment in MK-/- mice. To test the possibility that $\mathrm{MK}$ regulates astrocytosis depending on the brain area considered, we also assessed the effects of amphetamine in the hippocampus of $\mathrm{MK}-/-$ and WT mice (Figure 3(a)). Amphetamine induced different effects in WT and MK-/- mice (Figure 3). In contrast to the astrocytic response in the striatum, a significant decrease of GFAP+ astrocytes in amphetaminetreated MK-/- mice compared to WT mice (Figure 3(b)) was observed. The data demonstrate a regional-specific regulation of amphetamine-induced astrocytosis by MK.

\subsection{Genetic Inactivation of Midkine Differentially Regulates} LPS-Induced Striatal Gliosis. MK is not only found upregulated in the brain after administration of different drugs of abuse. The cerebral levels of expression of MK are increased in different diseases that share neuroinflammation as a common pathogenic mechanism, including ischemia and neurodegenerative diseases [20]. To test the possibility that MK regulates the glial response depending on the inflammatory stimulus used, we assessed the effects of LPS in MK-/and WT mice. As expected, a low dose of LPS $(0.5 \mathrm{mg} / \mathrm{kg})$ induced a moderate $\sim 2$-fold increase in the number of GFAP+ cells in the striatum of WT mice, an effect that was completely absent in $\mathrm{MK}-/-$ mice (Figure 4 ). In the case of microglia, LPS induced a robust response in both genotypes (Figure 5). However, compared to their corresponding salinepaired control groups, the increases in the number of Iba$1+$ cells in the striatum after LPS administration tended to be similar in WT and MK-/- mice (Figure 5(b)). The data demonstrate that MK modulates the astrocytic, but not microglial, response induced by LPS in the striatum.

3.4. Effect of Amphetamine on Y-Maze Behavior. The data presented here demonstrate for the first time an important role of $\mathrm{MK}$ in the modulation of the neuroinflammatory processes induced by amphetamine in the striatum. These processes have been related to the cognitive deficits caused by amphetamines abuse in humans [6]. Thus, we next tested the possibility that endogenous MK modulates the cognitive effects caused by a 10-day amphetamine treatment during adolescence, a stage especially vulnerable to the cognitive deficits induced by these drugs [23, 31]. Six days after the last amphetamine (or saline) administration, we assessed for the first time the behavior of six-week-old mice from both genotypes on the Y-maze (Figure 6). To test the possible longterm effects of amphetamine treatment during adolescence on the behavioral performance of WT and MK-/- mice on a memory task, we tested them again one week (7week-old mice) and three weeks later (9-week-old mice). First, it was found that control (saline-treated) WT and $\mathrm{MK}-1-$ mice efficiently established spatial memory in a similar manner (Figures 6(a)-6(c)). Amphetamine treatment during adolescence tended to impair the recognition memory in the Y-maze in 6-week-old MK-/- mice (Figure 6(a)). This amphetamine-induced impairment of the recognition memory was exacerbated in 7-week-old MK-/- compared to WT mice (Figure 6(b)). However, this effect of amphetamine in recognition memory of 6- and 7-week-old MK-/- mice 

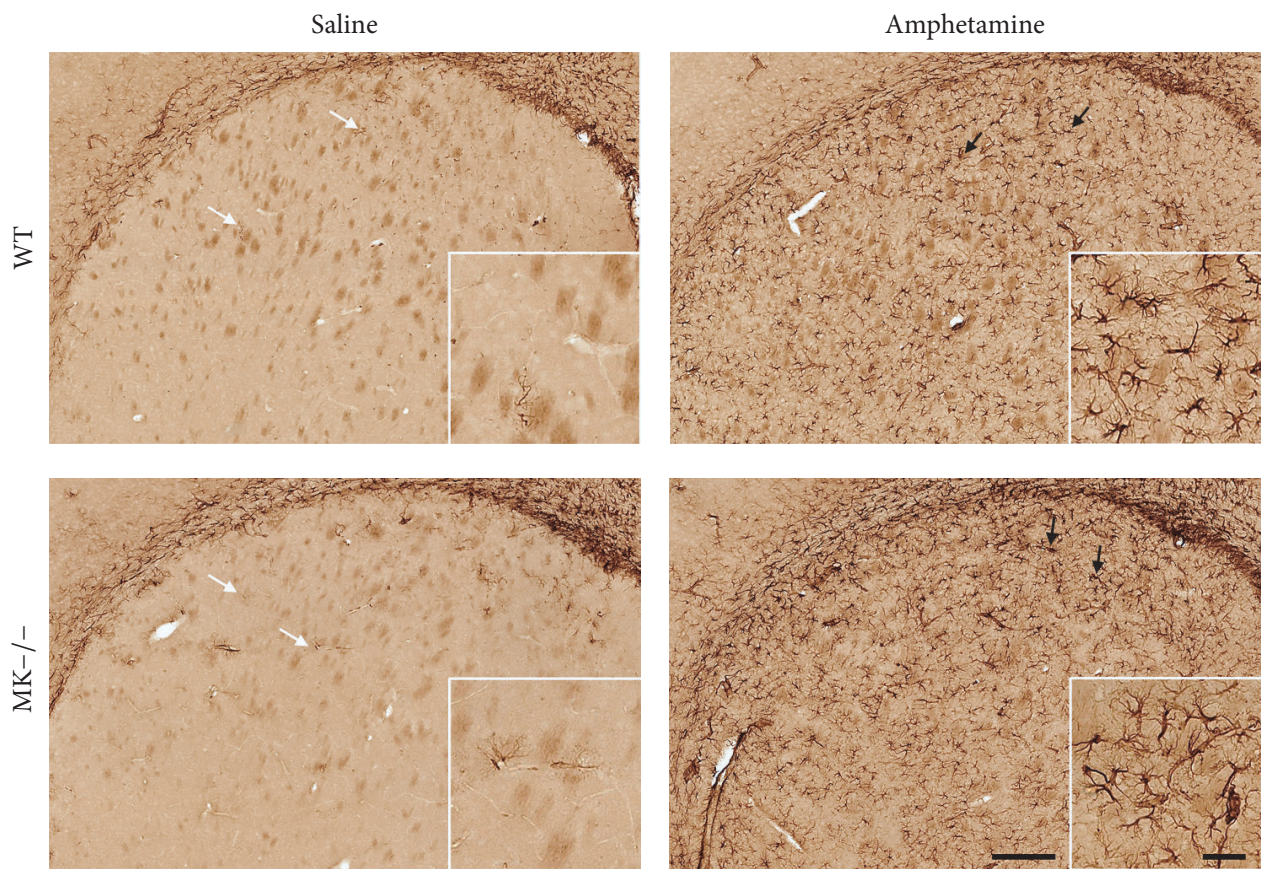

(a)

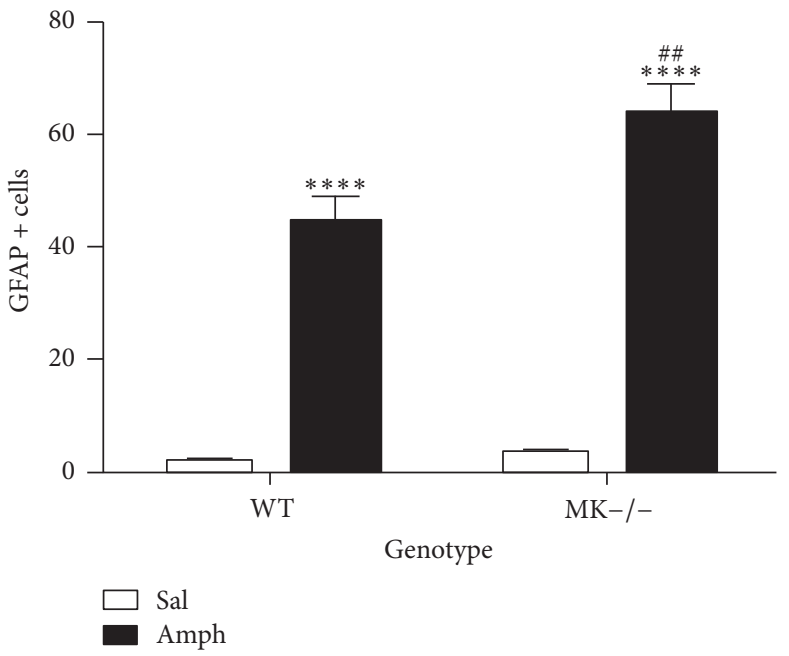

(b)

FIGURE 1: Amphetamine induces astrocytosis in the striatum of WT and MK-/- mice. (a) Photomicrographs are from GFAP-immunostained striatal sections of saline- (Sal-) or amphetamine- (Amph-) treated animals. Amphetamine induced reactive astrocytes characterized by larger densely stained bodies with longer and extensive processes (black arrows) compared to saline-treated mice (white arrows). (b) The graph represents quantification of data (mean \pm SEM) obtained from the counts of GFAP-positive cells in standardized areas of the striatum. Significant effects of the genotype $\left(F_{(1,16)}=8.051, P=0.01\right)$, the treatment $\left(F_{(1,16)}=200.3, P<0.0001\right)$, and genotype by treatment variant interaction $\left(F_{(1,16)}=5.896, P=0.03\right)$ were found. ${ }^{* * * *} P<0.0001$ versus Sal. ${ }^{\# \#} P<0.01$ versus WT. Scale bar $=200 \mu \mathrm{m}$. Magnified inset $=$ $50 \mu \mathrm{m}$.

was found to be transient since it was abolished in 9-weekold mice (Figure 6(c)). The data indicate that the cognitive impairment caused by periadolescent amphetamine treatment is modulated by endogenous MK.

\section{Discussion}

According to the European Monitoring Centre for Drugs and Drug Addiction, ever in lifetime use of amphetamines among young people in Europe varies considerably, with levels of $30-70 \%$. Despite widespread use of amphetaminetype stimulants, the medical consequences of these drugs abuse and the mechanisms underlying them are only partially understood. These drugs cause neuroinflammation [1], a pathogenic mechanism contributing to amphetamineinduced dopaminergic injury in the nigrostriatal pathway [32]. Accordingly, significant increases in the prevalence of PD in amphetamine-type drug abusers have been 

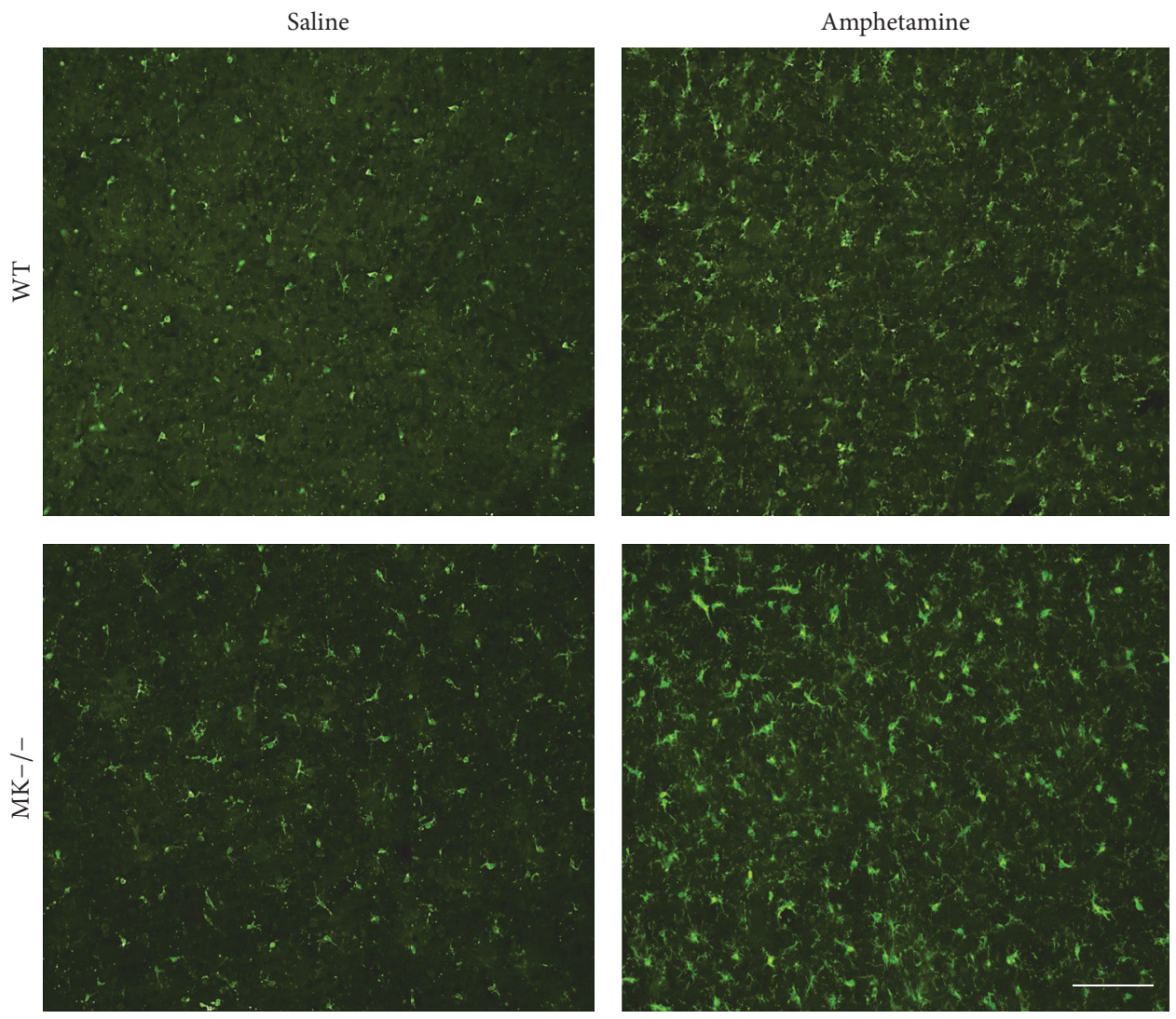

(a)

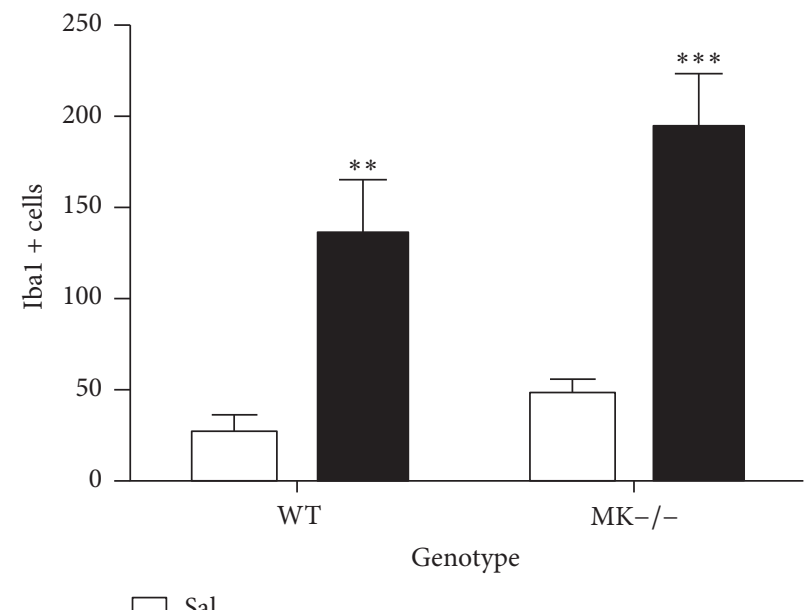

Sal

Amph

(b)

Figure 2: Amphetamine induces microgliosis in the striatum of WT and MK-/- mice. (a) Photomicrographs are from Iba-1-immunostained striatal sections of saline- (Sal-) or amphetamine- (Amph-) treated animals. (b) The graph represents quantification of data (mean \pm SEM) obtained from the counts of Iba-1-positive cells in standardized areas of the striatum. Significant effects of the genotype $\left(F_{(1,10)}=4.597\right.$, $P=0.05)$ and treatment $\left(F_{(1,10)}=46.12, P<0.0001\right)$ were found. ${ }^{* *} P<0.01$ and ${ }^{* * *} P<0.001$ versus Sal. Scale bar $=200 \mu \mathrm{m}$.

reported $[7,8]$. In the present work, we have confirmed that amphetamine-induced astrogliosis in the striatum, a hallmark of amphetamine-type drugs-induced neuroinflammation, is potentiated by genetic inactivation of MK [21]. More importantly, we demonstrate for the first time that amphetamine-induced striatal microglial response is also enhanced in $\mathrm{MK}-/-$ mice. The data indicate that $\mathrm{MK}$ is a genetic factor that regulates the neuroinflammatory effects induced by this type of psychostimulants. In this context, it is also important to note that MK expression and signaling are 

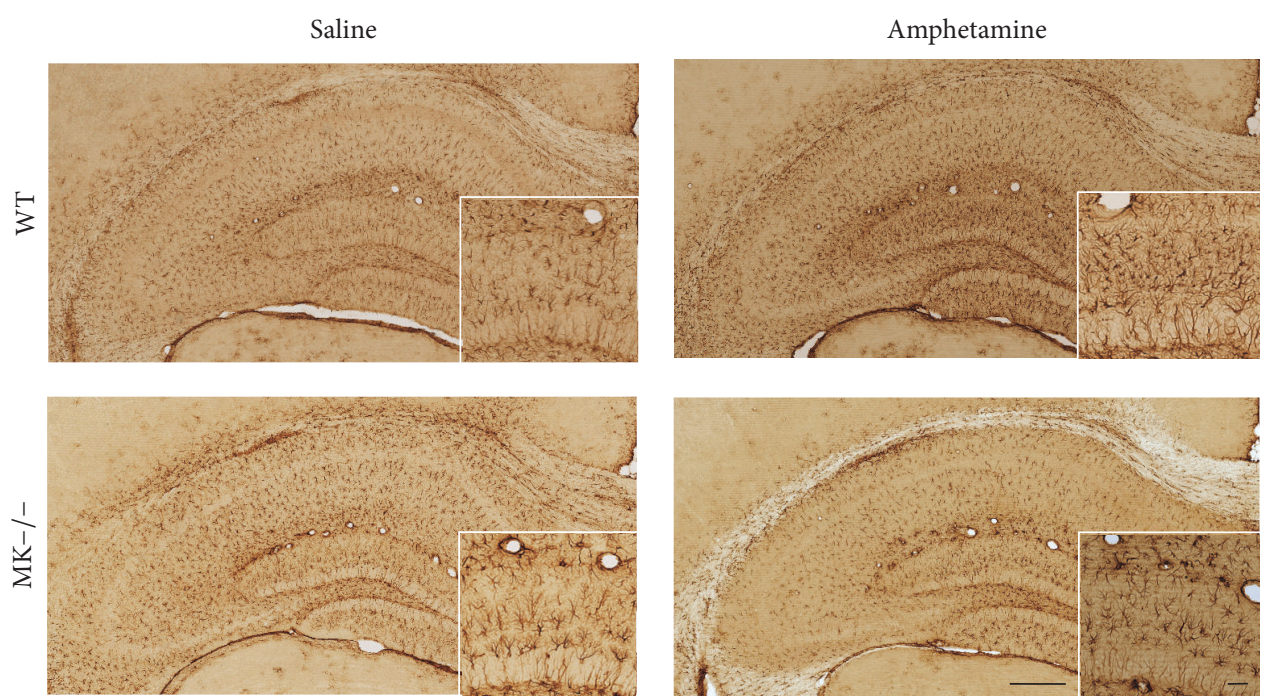

(a)

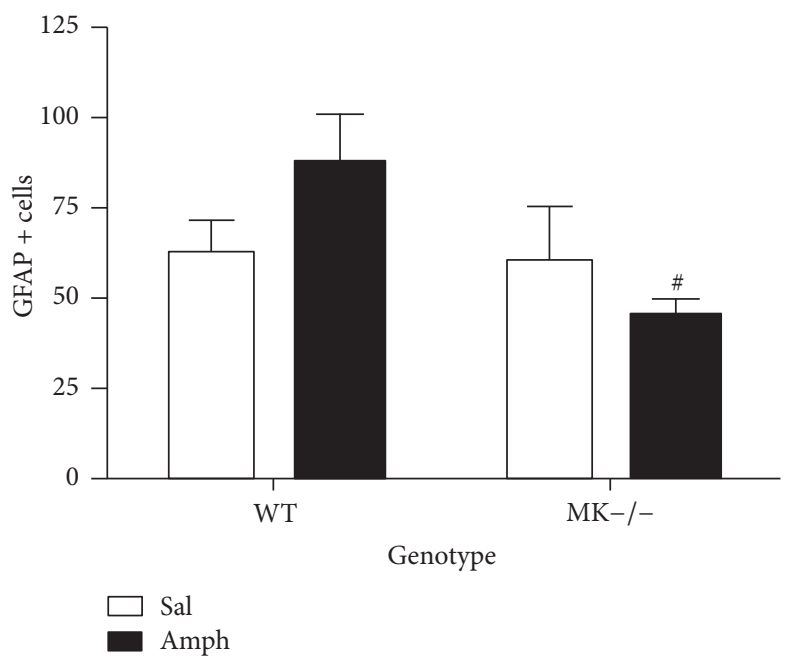

(b)

FIGURE 3: Amphetamine-induced astrocytosis in the hippocampus of WT and MK-/- mice. (a) Photomicrographs are from GFAPimmunostained hippocampal sections of saline- (Sal-) or amphetamine- (Amph-) treated animals. (b) The graph represents quantification of data (mean \pm SEM) obtained from the counts of GFAP-positive cells in standardized areas of the CA1 region of hippocampus. A significant effect of the genotype $\left(F_{(1,12)}=4.88, P=0.04\right)$ was found. ${ }^{\#} P<0.05$ versus WT. Scale bar $=200 \mu \mathrm{m}$. Magnified inset $=50 \mu \mathrm{m}$.

activated in the brain after administration of different drugs of abuse [33-35]. Taking together, our data suggest that the previously shown neuroprotective effects of MK against druginduced neurotoxicity $[20,36]$ could be related to its ability to prevent neuroinflammation.

The counteractive effect of MK against amphetamine astrogliosis seems to be region-specific since it is observed in the striatum, the main area affected by the neurotoxic effects of amphetamine, but not in the hippocampus. One possible explanation for these differences could be related to the different pattern of expression of MK after injury in both areas. While increased expression of MK is found in GFAP+ astrocytes in the injured mouse hippocampus [37], MK expression in the neurodegenerative nigrostriatal pathway is mainly found in neurons [20]. Thus, it is reasonable to hypothesize that constitutive genetic deletion of MK could cause different effects in response to injury depending on the area considered.

Midkine expression levels in the brain are also upregulated in different pathologies characterized by overt neuroinflammation [3, 10, 20,38]. Midkine is known to exert neuroprotective effects in some of these pathologies including Alzheimer's disease [18] and brain ischemia [39]. Thus, it is reasonable to hypothesize that the ability of $\mathrm{MK}$ to limit neuroinflammation could contribute to its neuroprotective actions in different pathological contexts. However, our data indicate that microglial response after LPS administration is not significantly regulated by MK. In contrast, LPS-induced striatal astrogliosis was blocked by genetic inactivation of MK. The data demonstrate a differential regulation of astrocytosis by MK depending on the inflammatory stimulus. The data presented here provide novel insights in the 

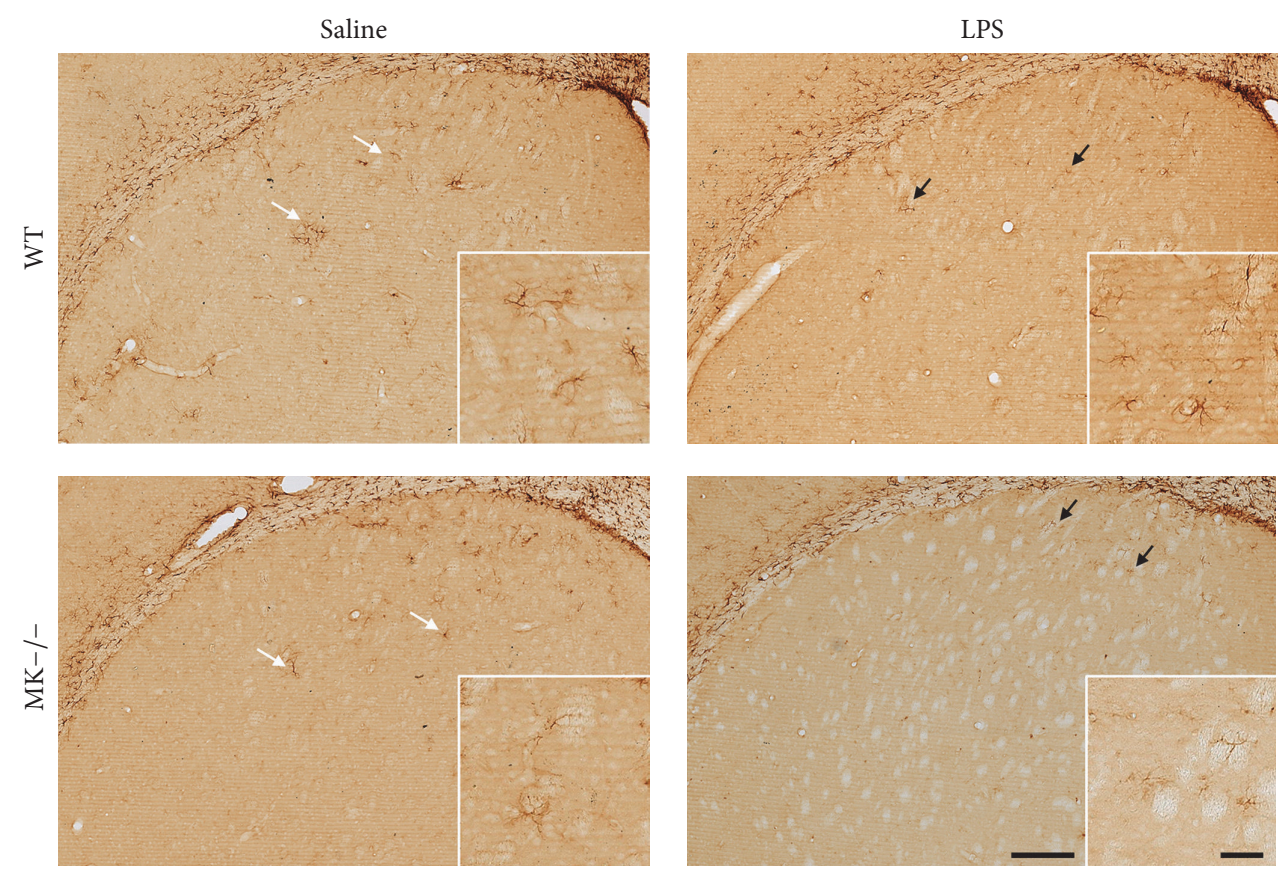

(a)

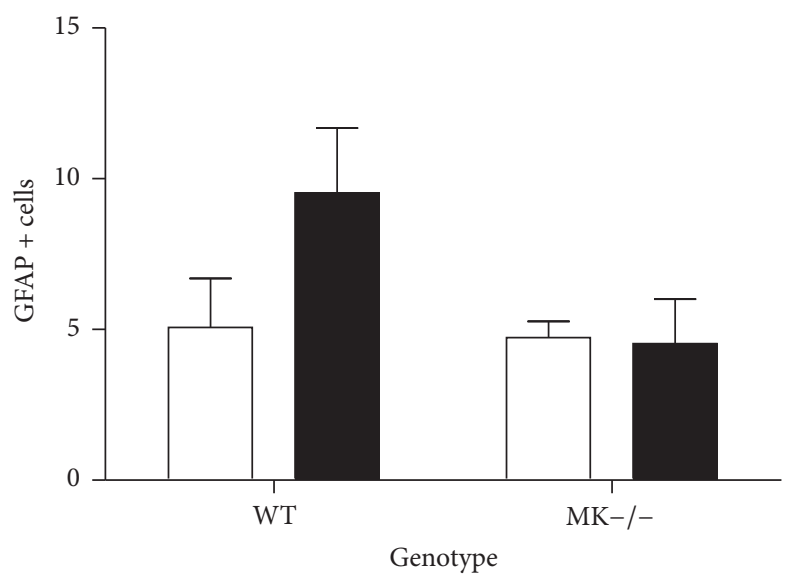

Sal

LPS

(b)

FIGURE 4: LPS-induced astrocytosis in the striatum of WT and MK-/- mice. (a) Photomicrographs are from GFAP-immunostained striatal sections of saline- (Sal-) treated or $0.5 \mathrm{mg} / \mathrm{kg}$ lipopolysaccharide- (LPS-) treated animals. (b) The graph represents quantification of data (mean \pm SEM) obtained from the counts of GFAP-positive cells in standardized areas of the striatum. Scale bar $=200 \mu \mathrm{m}$. Magnified inset $=$ $50 \mu \mathrm{m}$.

mechanisms and roles played by MK in CNS disorders in which astrogliosis is known to play pivotal roles. For instance, $\mathrm{MK}$ is expressed in senile plaques of Alzheimer's disease patients [40]. Astrocytosis facilitates $\mathrm{A} \beta$ plaque deposition in Alzheimer's disease [41] suggesting the interesting possibility that MK decreases $A \beta$ plaque deposition [18] through its ability to prevent astrogliosis.

The mechanism of action of MK supports our findings. One receptor for MK is Receptor Protein Tyrosine Phosphatase $\beta / \zeta(\operatorname{RPTP} \beta / \zeta)$ (a.k.a. PTPRZ1) [42]. MK binds to $\mathrm{RPTP} \beta / \zeta$ and inactivates its phosphatase activity. Inhibition of the phosphatase activity of RPTP $\beta / \zeta$ by MK binding regulates the tyrosine phosphorylation levels of substrates of $\operatorname{RPTP} \beta / \zeta$ which are known regulators of neuroinflammatory processes such as TrkA [43]. Signaling pathways downstream of $\mathrm{MK} / \mathrm{RPTP} \beta / \zeta$ which are also known to participate in gliosis include MAPK pathways [10]. Further studies are needed to test the possible involvement of these signaling pathways in the modulatory actions of MK in neuroinflammation.

Overall, the data presented here are relevant because the roles of MK in promoting inflammation had been described in detail in peripheral organs such as kidney and liver [10] 

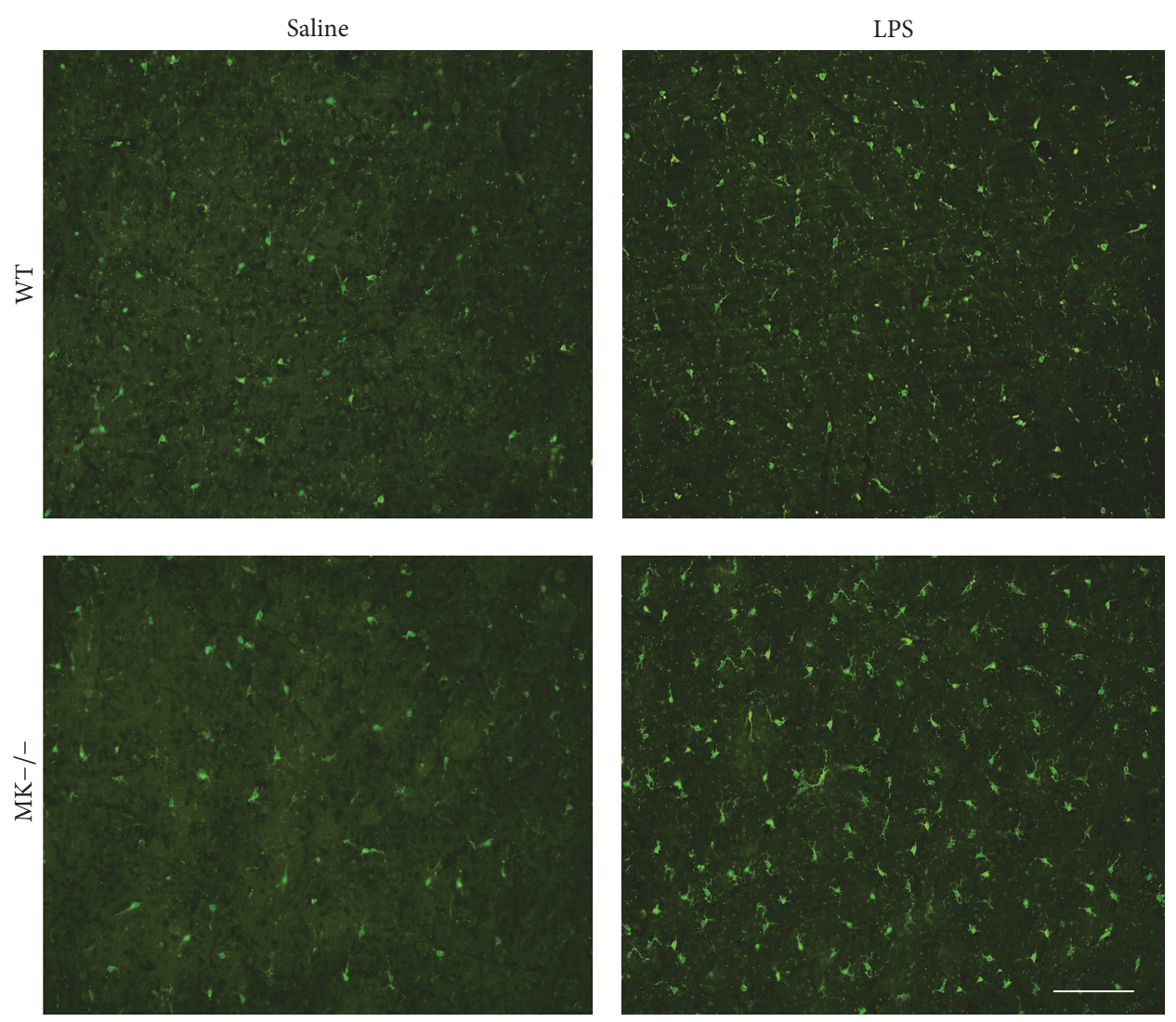

(a)

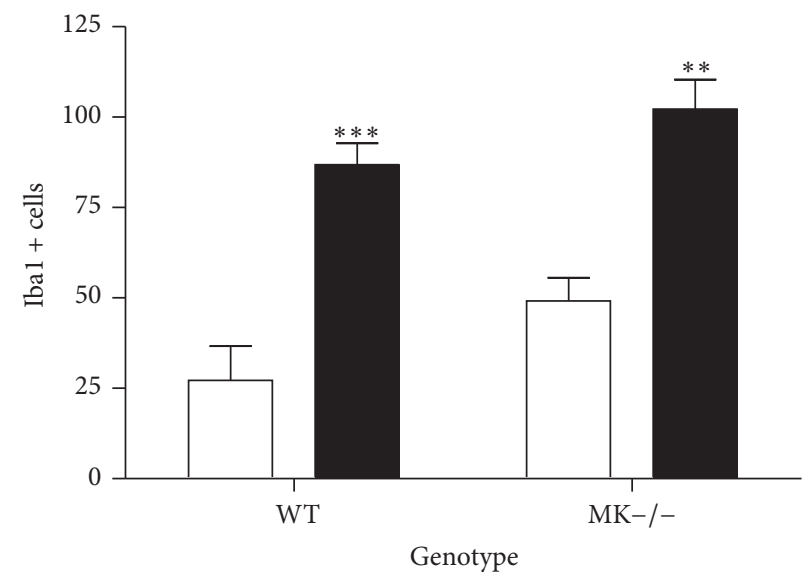

(b)

FIGURE 5: LPS-induced microgliosis in the striatum of WT and MK-/- mice. (a) Photomicrographs are from Iba-1-immunostained striatal sections of saline- (Sal-) treated or $0.5 \mathrm{mg} / \mathrm{kg}$ lipopolysaccharide- (LPS-) treated animals. (b) The graph represents quantification of data (mean \pm SEM) obtained from the counts of Iba-1-positive cells in standardized areas of the striatum. Significant effects of the genotype $\left(F_{(1,12)}\right.$ $=5.17, P=0.04)$ and treatment $\left(F_{(1,12)}=47.41, P<0.0001\right)$ were found. ${ }^{* *} P<0.01$ and ${ }^{* * *} P<0.001$ versus Sal. Scale bar $=200 \mu \mathrm{m}$.

but little was known about a possible role of MK in central inflammation. We now demonstrate for the first time that MK is a novel modulator of amphetamine-induced neuroinflammation in a brain area-dependent manner. We also show that MK differentially regulates astrogliosis depending on the noxious stimulus that triggers neuroinflammatory processes.
Our data support the need of further studies to dissect the specific modulatory roles of MK on neuroinflammation in the different brain pathologies in which MK has been shown to be upregulated.

In addition to its involvement in neurotoxicity and neurodegeneration, neuroinflammation significantly contributes 


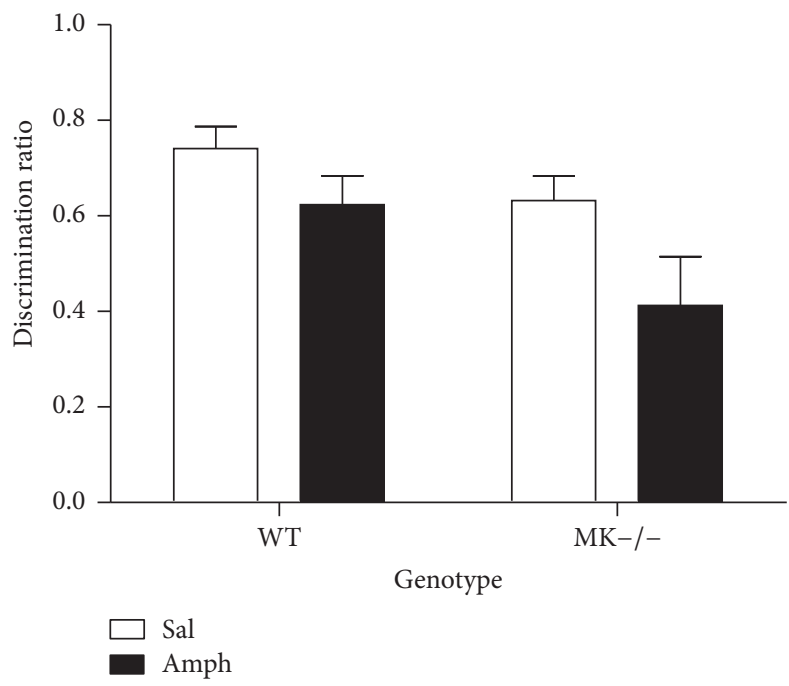

(a) Six weeks old

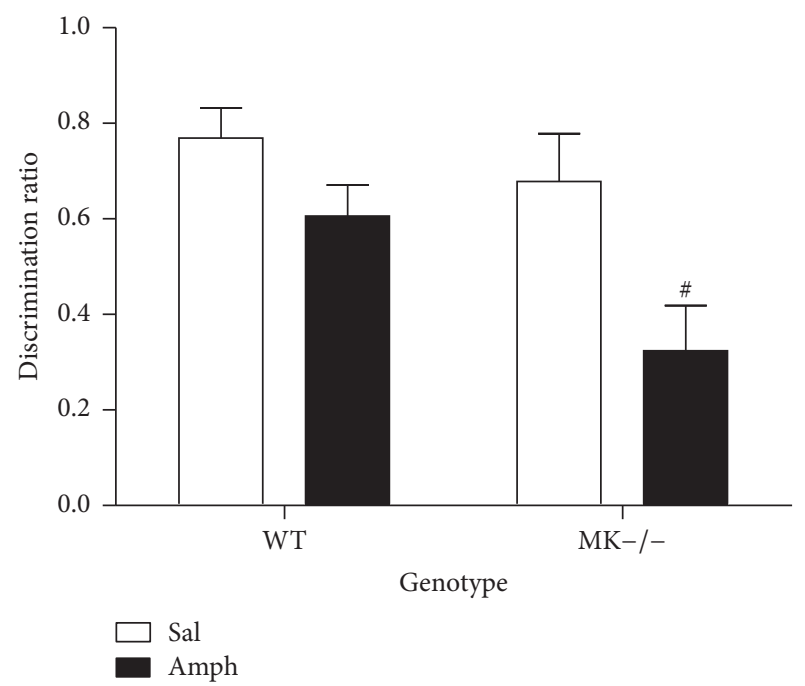

(b) Seven weeks old

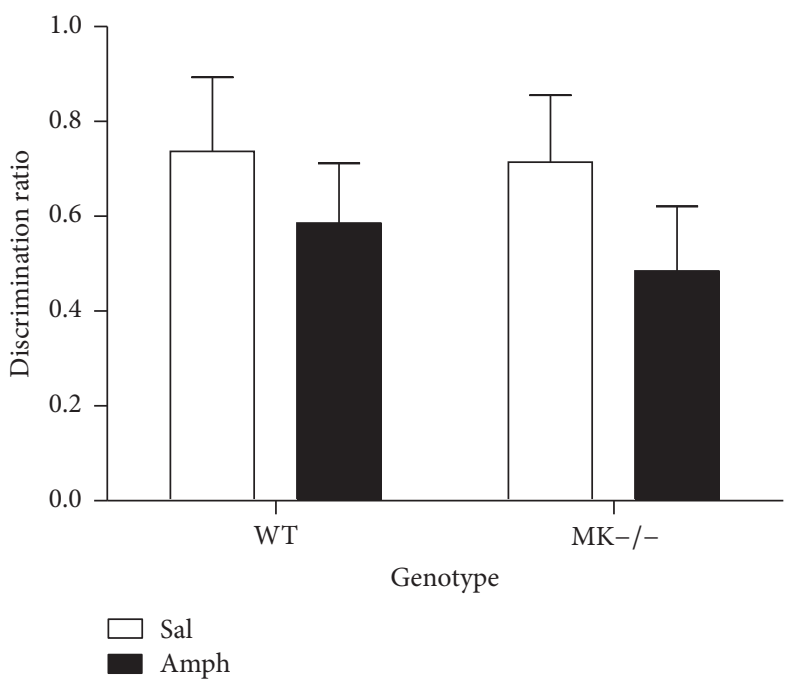

(c) Nine weeks old

Figure 6: Behavioral performance in the Y-maze of WT and MK-/- mice treated with amphetamine during adolescence. (a) Figure shows mean \pm SEM of discrimination ratio for 6-week-old WT and MK-/- mice pretreated with amphetamine during adolescence. Significant effects of the genotype $\left(F_{(1,44)}=5.04, P=0.03\right)$ and the treatment $\left(F_{(1,44)}=6.03, P=0.02\right)$ were found. (b) Figure shows mean \pm SEM of discrimination ratio for 7-week-old WT and MK-/- mice pretreated with amphetamine. Significant effects of the genotype $\left(F_{(1,44)}=5.1\right.$, $P=0.03)$ and treatment $\left(F_{(1,44)}=10.46, P=0.002\right)$ were found. (c) Figure shows mean \pm SEM of discrimination ratio for 9-week-old WT and $\mathrm{MK}-/-$ mice pretreated with amphetamine. ${ }^{\#} P<0.05$ versus WT.

to behavioral alterations possibly by affecting synaptic function [44]. Accordingly, new experimental therapeutics provide correlation between reduction of neuroinflammation and improved cognitive impairment in Alzheimer's disease [45]. Interestingly, behavioral changes associated with amphetamine treatment during adolescence are cognitive deficits [31]. Our data demonstrate that periadolescent amphetamine treatment has modest consequences in WT mice in the Y-maze test but causes a transient disruption of the working memory in the Y-maze in $\mathrm{MK}-/-$ mice. The data suggest that genetic inactivation of MK confers greater vulnerability to the transient cognitive impairment associated with a periadolescent amphetamine treatment. It is tempting to connect these behavioral data with the reduced amphetamine-induced astrocytosis in the MK-/- mouse hippocampus, a relevant area for recognition memory. However, in the case of this type of drugs, it has been recently shown that neuroinflammatory processes induced by methamphetamine in the striatum underlie cognitive deficits in this drug's addicts [6]. Our data support the correlation between cognitive deficits and enhanced amphetamineinduced striatal neuroinflammation in $\mathrm{MK}-/-$ mice.

\section{Conclusions}

The data demonstrate for the first time that MK is a novel regulator of neuroinflammation in a stimulus and brain region-dependent manner. The data presented here indicate 
that MK limits amphetamine-induced striatal neuroinflammation. The data also demonstrate that periadolescent amphetamine treatment in mice results in transient disruption of learning and memory processes in $\mathrm{MK}-/-$ mice, effect that could be related to the absence of the counteractive actions of $\mathrm{MK}$ in striatal neuroinflammation.

\section{Competing Interests}

The authors do not have any conflict of interests to declare.

\section{Acknowledgments}

This work has been supported by Grants SAF2014-56671$\mathrm{R}$ from Ministerio de Economía y Competitividad of Spain and USP-BS-APP03/2014 from Universidad CEU San Pablo and Banco de Santander. Marta Vicente-Rodríguez and Rosalía Fernández-Calle are supported by fellowships from Fundación Universitaria San Pablo CEU.

\section{References}

[1] V. Coelho-Santos, J. Gonçalves, C. Fontes-Ribeiro, and A. P. Silva, "Prevention of methamphetamine-induced microglial cell death by TNF- $\alpha$ and IL- 6 through activation of the JAKSTAT pathway," Journal of Neuroinflammation, vol. 9, article 103, 2012.

[2] L. S. Feder and D. L. Laskin, "Regulation of hepatic endothelial cell and macrophage proliferation and nitric oxide production by GM-CSF, M-CSF, and IL-1 $\beta$ following acute endotoxemia," Journal of Leukocyte Biology, vol. 55, pp. 507-513, 1994.

[3] L. C. Freeman and J. P.-Y. Ting, "The pathogenic role of the inflammasome in neurodegenerative diseases," Journal of Neurochemistry, vol. 136, supplement 1, pp. 29-38, 2016.

[4] V. Sanchez-Guajardo, C. J. Barnum, M. G. Tansey, and M. Romero-Ramos, "Neuroimmunological processes in Parkinson's disease and their relation to $\alpha$-synuclein: microglia as the referee between neuronal processes and peripheral immunity," ASN Neuro, vol. 5, no. 2, pp. 113-139, 2013.

[5] L. Qin, X. Wu, M. L. Block et al., "Systemic LPS causes chronic neuroinflammation and progressive neurodegeneration," Glia, vol. 55, no. 5, pp. 453-462, 2007.

[6] I. N. Krasnova, Z. Justinova, and J. L. Cadet, "Methamphetamine addiction: involvement of CREB and neuroinflammatory signaling pathways," Psychopharmacology, vol. 233, no. 10, pp. 1945-1962, 2016.

[7] R. C. Callaghan, J. K. Cunningham, J. Sykes, and S. J. Kish, "Increased risk of Parkinson's disease in individuals hospitalized with conditions related to the use of methamphetamine or other amphetamine-type drugs," Drug and Alcohol Dependence, vol. 120, no. 1-3, pp. 35-40, 2012.

[8] K. Curtin, A. E. Fleckenstein, R. J. Robison, M. J. Crookston, K. R. Smith, and G. R. Hanson, "Methamphetamine/amphetamine abuse and risk of Parkinson's disease in Utah: a populationbased assessment," Drug and Alcohol Dependence, vol. 146, no. 1, pp. 30-38, 2015.

[9] A. J. Nimmo and R. Vink, "Recent patents in CNS drug discovery: the management of inflammation in the central nervous system," Recent Patents on CNS Drug Discovery, vol. 4, no. 2, pp. 86-95, 2009.
[10] T. Muramatsu, "Structure and function of midkine as the basis of its pharmacological effects," British Journal of Pharmacology, vol. 171, no. 4, pp. 814-826, 2014.

[11] L. T. Weckbach, A. Gola, M. Winkelmann et al., "The cytokine midkine supports neutrophil trafficking during acute inflammation by promoting adhesion via $\beta_{2}$ integrins (CD11/CD18)," Blood, vol. 123, no. 12, pp. 1887-1896, 2014.

[12] M. Horiba, K. Kadomatsu, E. Nakamura et al., "Neointima formation in a restenosis model is suppressed in midkinedeficient mice," Journal of Clinical Investigation, vol. 105, no. 4, pp. 489-495, 2000.

[13] W. Sato, K. Kadomatsu, Y. Yuzawa et al., "Midkine is involved in neutrophil infiltration into the tubulointerstitium in ischemic renal injury," The Journal of Immunology, vol. 167, no. 6, pp. 3463-3469, 2001.

[14] T. Takada, K. Toriyama, H. Muramatsu, X. J. Song, S. Torii, and T. Muramatsu, "Midkine, a retinoic acid-inducible heparinbinding cytokine in inflammatory responses: chemotactic activity to neutrophils and association with inflammatory synovitis," Journal of Biochemistry, vol. 122, no. 2, pp. 453-458, 1997.

[15] Y. Sonobe, H. Li, S. Jin et al., "Midkine inhibits inducible regulatory $\mathrm{T}$ cell differentiation by suppressing the development of tolerogenic dendritic cells," The Journal of Immunology, vol. 188, no. 6, pp. 2602-2611, 2012.

[16] J. Wang, H. Takeuchi, Y. Sonobe et al., "Inhibition of midkine alleviates experimental autoimmune encephalomyelitis through the expansion of regulatory T cell population," Proceedings of the National Academy of Sciences of the United States of America, vol. 105, no. 10, pp. 3915-3920, 2008.

[17] A. Muramoto, S. Imagama, T. Natori et al., "Midkine overcomes neurite outgrowth inhibition of chondroitin sulfate proteoglycan without glial activation and promotes functional recovery after spinal cord injury," Neuroscience Letters, vol. 550, pp. 150 155,2013

[18] T. Muramatsu, "Midkine: a promising molecule for drug development to treat diseases of the central nervous system," Current Pharmaceutical Design, vol. 17, no. 5, pp. 410-423, 2011.

[19] E. Gramage and G. Herradón, “Connecting Parkinson’s disease and drug addiction: common players reveal unexpected disease connections and novel therapeutic approaches," Current Pharmaceutical Design, vol. 17, no. 5, pp. 449-461, 2011.

[20] G. Herradõn and C. Pérez-García, "Targeting midkine and pleiotrophin signalling pathways in addiction and neurodegenerative disorders: Recent progress and perspectives," British Journal of Pharmacology, vol. 171, no. 4, pp. 837-848, 2014.

[21] E. Gramage, Y. B. Martín, P. Ramanah, C. Pérez-García, and G. Herradón, "Midkine regulates amphetamine-induced astrocytosis in striatum but has no effects on amphetamine-induced striatal dopaminergic denervation and addictive effects: functional differences between pleiotrophin and midkine," Neuroscience, vol. 190, pp. 307-317, 2011.

[22] L.-M. Mao, B. Xue, D.-Z. Jin, and J. Q. Wang, "Dynamic increases in AMPA receptor phosphorylation in the rat hippocampus in response to amphetamine," Journal of Neurochemistry, vol. 133, no. 6, pp. 795-805, 2015.

[23] D. I. Lubman, M. Yücel, and W. D. Hall, "Substance use and the adolescent brain: a toxic combination?" Journal of Psychopharmacology, vol. 21, no. 8, pp. 792-794, 2007.

[24] E. Nakamura, K. Kadomatsu, S. Yuasa et al., "Disruption of the midkine gene (Mdk) resulted in altered expression of a calcium binding protein in the hippocampus of infant mice and their 
abnormal behaviour," Genes to Cells, vol. 3, no. 12, pp. 811-822, 1998.

[25] A. Jacob, L. K. Hensley, B. D. Safratowich, R. J. Quigg, and J. J. Alexander, "The role of the complement cascade in endotoxininduced septic encephalopathy," Laboratory Investigation, vol. 87, no. 12, pp. 1186-1194, 2007.

[26] E. Gramage, A. Putelli, M. J. Polanco et al., “The neurotrophic factor pleiotrophin modulates amphetamine-seeking behaviour and amphetamine-induced neurotoxic effects: evidence from pleiotrophin knockout mice," Addiction Biology, vol. 15, no. 4, pp. 403-412, 2010.

[27] E. Gramage, L. Rossi, N. Granado, R. Moratalla, and G. Herradón, "Genetic inactivation of pleiotrophin triggers amphetamine-induced cell loss in the substantia nigra and enhances amphetamine neurotoxicity in the striatum," Neuroscience, vol. 170, no. 1, pp. 308-316, 2010.

[28] E. Gramage, N. Del Olmo, A. Fole, Y. B. Martín, and G. Herradón, "Periadolescent amphetamine treatment causes transient cognitive disruptions and long-term changes in hippocampal LTP depending on the endogenous expression of pleiotrophin," Addiction biology, vol. 18, no. 1, pp. 19-29, 2013.

[29] N. del Olmo, E. Gramage, L. F. Alguacil, P. Pérez-Pinera, T. F. Deuel, and G. Herradón, "Pleiotrophin inhibits hippocampal long-term potentiation: a role of pleiotrophin in learning and memory," Growth Factors, vol. 27, no. 3, pp. 189-194, 2009.

[30] N. T. Boyle and T. J. Connor, "Methylenedioxymethamphetamine ('Ecstasy')-induced immunosuppression: a cause for concern?" British Journal of Pharmacology, vol. 161, no. 1, pp. 17-32, 2010.

[31] T. Featherby, M. Van Den Buuse, D. I. Lubman, and A. J. Lawrence, "Persistent downregulation of hippocampal CREB mRNA parallels a Y-maze deficit in adolescent rats following semi-chronic amphetamine administration," British Journal of Pharmacology, vol. 154, no. 2, pp. 417-428, 2008.

[32] R. Moratalla, A. Khairnar, N. Simola et al., "Amphetamine-related drugs neurotoxicity in humans and in experimental animals: main mechanisms," Progress in Neurobiology, vol. S03010082, no. 15, pp. 00100-00108, 2015.

[33] L. Ezquerra, C. Pérez-García, E. Garrido et al., "Morphine and yohimbine regulate midkine gene expression in the rat hippocampus," European Journal of Pharmacology, vol. 557, no. 2-3, pp. 147-150, 2007.

[34] T. Flatscher-Bader and P. A. Wilce, "Impact of alcohol abuse on protein expression of midkine and excitatory amino acid transporter 1 in the human prefrontal cortex," Alcoholism: Clinical and Experimental Research, vol. 32, no. 10, pp. 18491858, 2008.

[35] Y. He, L. Xu, B. Li et al., "Macrophage-inducible C-type lectin/spleen tyrosine kinase signaling pathway contributes to neuroinflammation after subarachnoid hemorrhage in rats," Stroke, vol. 46, no. 8, pp. 2277-2286, 2015.

[36] G. Herradon, L. Ezquerra, E. Gramage, and L. F. Alguacil, “Targeting the pleiotrophin/receptor protein tyrosine phosphatase $\beta / \zeta$ signaling pathway to limit neurotoxicity induced by drug abuse," Mini-Reviews in Medicinal Chemistry, vol. 9, no. 4, pp. 440-447, 2009.

[37] Y. B. Kim, J. K. Ryu, H. J. Lee et al., "Midkine, heparin-binding growth factor, blocks kainic acid-induced seizure and neuronal cell death in mouse hippocampus," BMC Neuroscience, vol. 11, article 42, 2010.
[38] T. Kielian, "Multifaceted roles of neuroinflammation: the need to consider both sides of the coin," Journal of Neurochemistry, vol. 136, supplement 1, pp. 5-9, 2016.

[39] S. Otsuka, H. Sakakima, M. Sumizono, S. Takada, T. Terashi, and Y. Yoshida, "The neuroprotective effects of preconditioning exercise on brain damage and neurotrophic factors after focal brain ischemia in rats," Behavioural Brain Research, vol. 303, pp. 9-18, 2016.

[40] O. Yasuhara, H. Muramatsu, S. U. Kim, T. Muramatsu, H. Maruta, and P. L. McGeer, "Midkine, a novel neurotrophic factor, is present in senile plaques of Alzheimer disease," Biochemical and Biophysical Research Communications, vol. 192, no. 1, pp. 246-251, 1993.

[41] E. Rodriguez-Vieitez, R. Ni, B. Gulyás et al., "Astrocytosis precedes amyloid plaque deposition in Alzheimer APPswe transgenic mouse brain: a correlative positron emission tomography and in vitro imaging study," European Journal of Nuclear Medicine and Molecular Imaging, vol. 42, no. 7, pp. 1119-1132, 2015.

[42] N. Sakaguchi, H. Muramatsu, K. Ichihara-Tanaka et al., "Receptor-type protein tyrosine phosphatase $\zeta$ as a component of the signaling receptor complex for midkine-dependent survival of embryonic neurons," Neuroscience Research, vol. 45, no. 2, pp. 219-224, 2003.

[43] T. Shintani and M. Noda, "Protein tyrosine phosphatase receptor type $\mathrm{Z}$ dephosphorylates TrkA receptors and attenuates NGF-dependent neurite outgrowth of PC12 cells," The Journal of Biochemistry, vol. 144, no. 2, pp. 259-266, 2008.

[44] J. Di, L. S. Cohen, C. P. Corbo, G. R. Phillips, A. El Idrissi, and A. D. Alonso, "Abnormal tau induces cognitive impairment through two different mechanisms: synaptic dysfunction and neuronal loss," Scientific Reports, vol. 6, Article ID 20833, 2016.

[45] V. Echeverria, A. Yarkov, and G. Aliev, "Positive modulators of the $\alpha 7$ nicotinic receptor against neuroinflammation and cognitive impairment in Alzheimer's disease," Progress in Neurobiology, vol. 144, pp. 142-157, 2016. 


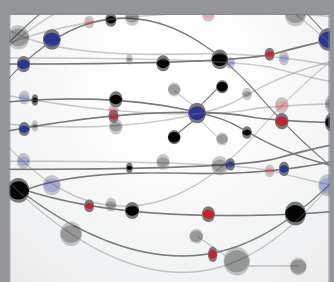

The Scientific World Journal
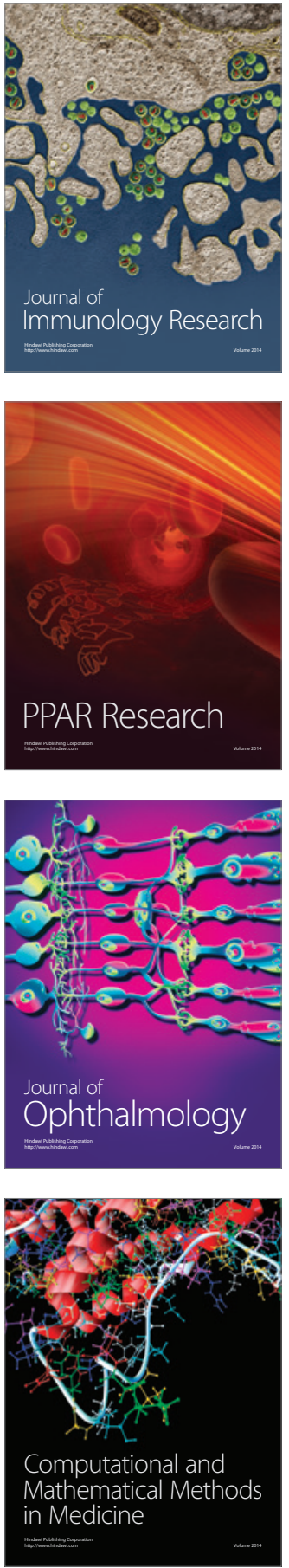

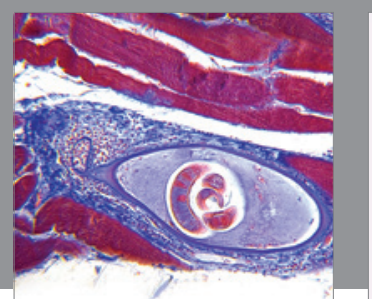

Gastroenterology Research and Practice

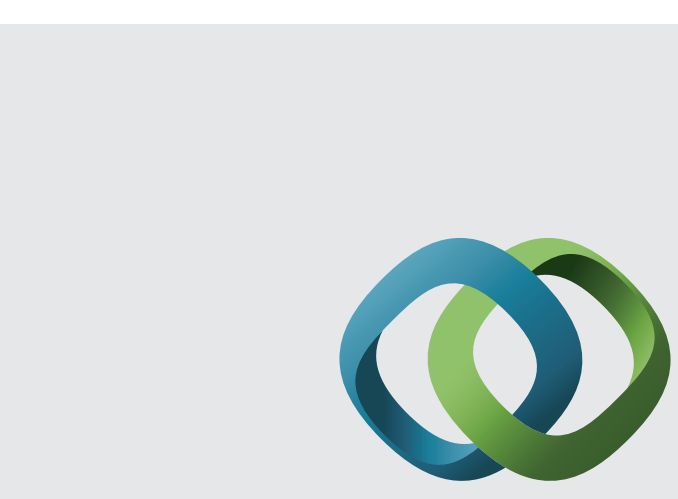

\section{Hindawi}

Submit your manuscripts at

http://www.hindawi.com
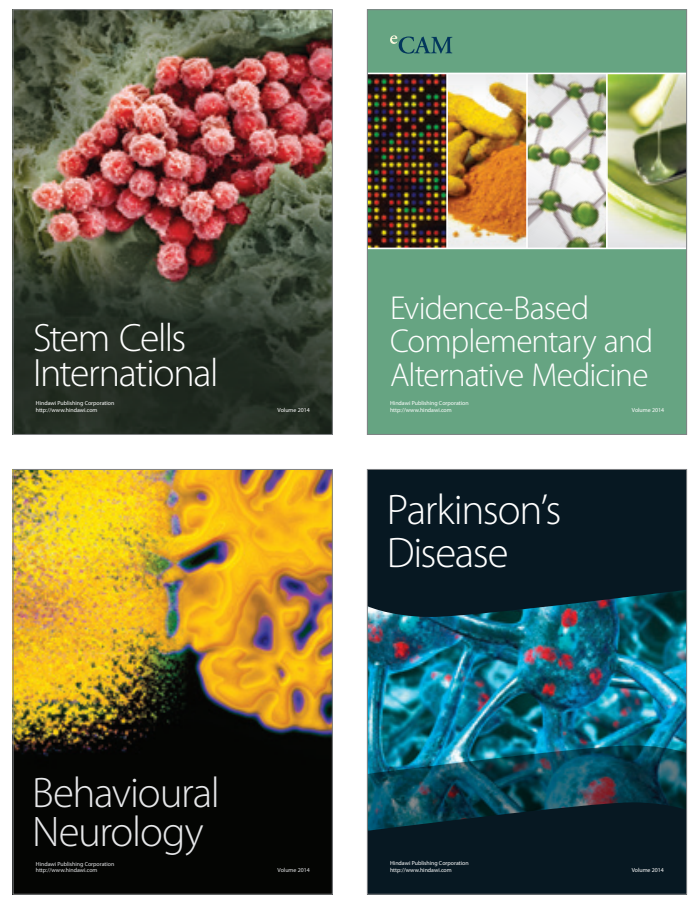
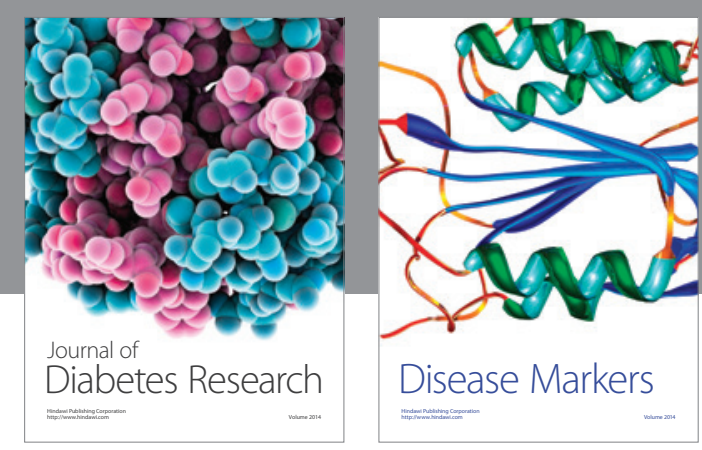

Disease Markers
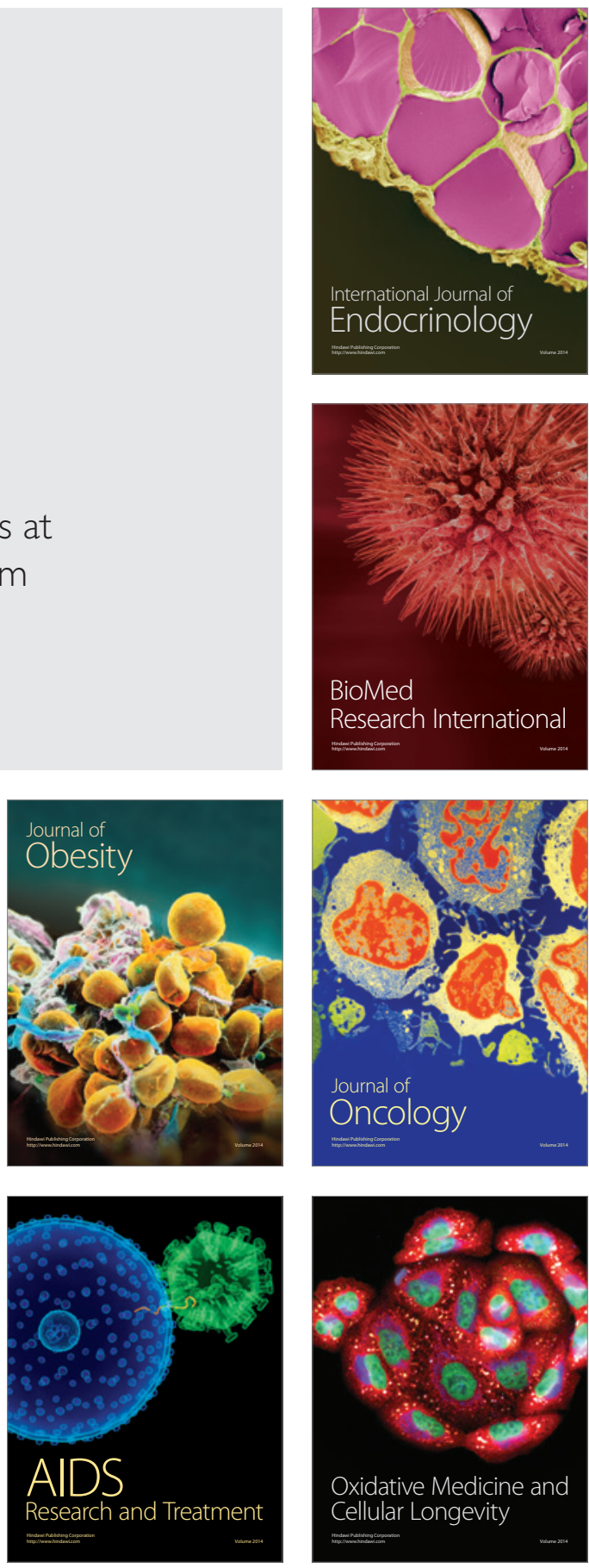